\title{
Del sentir impersonal. Los estudios de Mario Perniola sobre la era estética
}

\section{On impersonal feeling. Mario Perniola's studies on the aesthetics era}

Kathia Hanza*

Pontificia Universidad Católica del Perú

\section{Resumen}

El artículo analiza la comprensión de la estética de Perniola. De acuerdo con este, el estudio de la estética (aísthesis), en tanto esfera del sentir, proporciona ciertas claves interpretativas para la comprensión del mundo contemporáneo, que se caracteriza por el empobrecimiento de la experiencia individual y la incapacidad para sentir propiamente. La conformación del sentir actual, que ha devenido impersonal, es explica$\mathrm{da}$, por un lado, mediante la arqueología, que hace patentes las estratificaciones de lo ya sentido, y, por otro lado, mediante la genealogía, que descubre la dimensión activa del sentir.

Palabras clave: aísthesis, arqueología, estética, genealogía, sentir

* Doctora en Filosofía por la Universidad Johann Wolfgang Goethe, Frankfurt am Main, Alemania. Profesora asociada del Departamento de Humanidades de la PUCP y directora de la Biblioteca Central en dicha Universidad.

Contacto:khanza@pucp.pe 


\section{Abstract}

The article analizes Perniola's understanding of aesthetics. According to Perniola, the study of aesthetics (aísthesis) as a sphere of feeling provides interpretative clues for understanding of the contemporary world, characterized by the impoverishment of individual experience and the incapacity for proper feeling. The conformity of feeling, which has become impersonal nowadays, is explained on the one hand through archaeology, which makes visible the stratifications of the "already felt", and on the other hand, through genealogy, which discovers the active dimension of feeling.

Keywords: aísthesis, aesthetics, archaeology, genealogy, feel

En una reseña sobre un libro de Mario Perniola, El arte y su sombra (2000), Farris Wahbeh (2006: 495) observa que su autor se toma en serio el argumento estoico de que todo el conocimiento deriva de los sentidos, de que nada inmaterial existe. Ciertamente, buenas razones animan a Perniola a adoptar la posición según la cual todo lo existente está dotado de ánima, incluso lo tomado comúnmente como inanimado, en el largo debate filosófico sobre la ontología. Pero la razón más poderosa quizá sea que el neoestoicismo (Perniola 2014: 9) (neo, pues muchas cosas han cambiado desde que Zenón de Citio impartiese sus lecciones en la Stoa) aporta herramientas conceptuales precisas para comprender el hilarante y desquiciado mundo actual. En efecto, una posición abiertamente materialista puede a la vez identificar de manera crítica el impacto real de las ilusiones que nos pueblan y sostener lúcidamente criterios de discernimiento y acción. No hay por qué sumarse al coro de los "pia desideria de las 
almas bellas" (Perniola 2008: 14) ni sucumbir a la ilusión autista, cacofónica, especular. El materialismo toma como real el todopoderoso influjo del carnaval de ilusiones contemporáneo y lo desmenuza en aquello que parece menos material: la índole del sentir, pues ella es, sostiene Perniola, a fin de cuentas material.

Sin duda, es una empresa desafiante discutir las implicancias y consecuencias metafísicas del materialismo, pero no es una tarea que Perniola emprenda. El materialismo le sirve para detectar a qué experiencias está sometido el hombre hoy en día y también para aportar razones para su esclarecimiento y ponderación. Se trata de decir algo adecuado sobre la compleja experiencia del mundo contemporáneo, incluso si el punto de partida es uno de sus más obvios pero también confusos: la estética, la esfera del sentir (Perniola 2007: 43). La estética, porque ella es la vía regia para tomar en serio un asunto esencial: cómo hoy se nos ofrece a discreción un sinnúmero de posibilidades para sentir. Lo curioso es que ello no se traduce en una experiencia propia, pues esas posibilidades no significan nada en términos de un esfuerzo personal. Extraña condición. Como nunca, la esfera del sentir, esto es, la esfera de experiencia que resuena todavía en la palabra estética (aísthesis, sensación), se amplía a rasgos insospechados en el mundo de hoy, pero a la vez se empobrece y enrarece, porque no comporta ningún tipo de esfuerzo, de cuidado, de atención. Para tener una imagen vívida de esta condición, Perniola recurre a una comparación: "Para nuestros abuelos, los objetos, las personas, los sucesos estaban para ser sentidos, les hacían vivir una experiencia interior, que les causaba alegría o tristeza; se identificaban con ellos en lo sensorial, emotiva y espiritualmente, o, por el contrario, no los notaban o se negaban a notarlos. Mientras que, para nosotros, los objetos, las personas y los sucesos son algo ya sentido, que nos absorbe con una nota sensorial, emotiva y espiritual determinada de antemano" (2008: 28). 
Lo ya sentido es una expresión clave para lo que Perniola quiere dar a pensar. Su idea es que la estética contemporánea transforma "toda la vida sensitiva y emocional en algo exteriormente impenetrable" (2008: 38). Ello se debe a su naturaleza especular, patente en la conducta diaria: nos absorben la farmacología y la cosmética, no porque hayamos interiorizado nuestra libido, como podría plantear Freud, sino porque disolvemos nuestro cuerpo: lo tomamos como reflejo de entes externos (2008: 37-38). Perniola tampoco se alinea a la tradición de la crítica a la ideología desde Marx y de la fantasmagoría con Benjamin. No es cuestión de reconocer críticamente que hay un efecto espectral en la experiencia, de cuyo paroxismo Baudrillard dio cuenta para convertirse, con harta frecuencia, en una muletilla insufrible. Es, más bien, advertir la anulación de toda experiencia en aras de un reflejo impenetrable, un ya sentido inerte para todo término personal.

Cuando Perniola sostiene que "el sentir es inseparable del conocimiento y la voluntad” (2008: 95) ${ }^{1}$ resuena el sensualismo originario de la Stoa, pero también se condice con las máximas prácticas (convenienter vivere, solum honestum bonum est) de aquella antigua escuela filosófica ${ }^{2}$. El neoestoicismo, que el propio Perniola se atribuye, puede tomarse como eje de una gruesa comparación histórica. El término es raramente utilizado en el siglo XIX, aunque sí regularmente en el siglo $\mathrm{XX}^{3}$. Las guerras civiles y religiosas que indujeron

1 Se advierte que el materialismo de Perniola es de otro cuño que, por ejemplo, el propugnado por la Escuela de Frankfurt. La diferencia mayor puede percibirse con relación a Habermas, para quien la esfera del sentir concierne principalmente a lo "expresivo".

2 Sobre el estoicismo antiguo, véase el artículo de F. Böhling en el Historisches Wörterbuch der Philosophie. Darmstadt: Wissenschaftliche Buchgesellschaft. Tomo X, 1998, pp. 176-186.

3 Sobre el neoestoicismo, véase el artículo de K. A Blüher en el Historisches Wörterbuch der Philosophie. Tomo VI, 1984, pp. 777-779. 
al resurgimiento y desarrollo del estoicismo en la Europa del XVI quizá sean comparables a las de nuestros tiempos. Al menos en lo que concierne a la autonomía espiritual e intelectual, el neoestoicismo de ahora tiene en común con el de vieja data, incluido el del siglo XVI, que tal autonomía consiste en evitar el dogmatismo. Pero la diferencia principal radica en que, para nosotros, rechazar el dogmatismo no significa eo ipso actuar en consecuencia o, más aún, saberlo por la recta razón (Von Arnim 1964, vol. 3: 172-173 y 85).

\section{De abuelos: arqueología}

Volvamos a la comparación con nuestros abuelos. Es ciertamente difícil hacerse una idea de cómo sentían ellos. El asunto es harto lábil y uno cae fácilmente en tonterías. Con todo, intentemos por un momento imaginarnos un sentir anterior, aunque sea bajo la forma de la ficción. Así describe el joven Werther en una carta a su amigo Wilhelm cómo se siente:

Reina en mi espíritu una alegría admirable, muy parecida a las dulces alboradas de la primavera, de que gozo aquí con delicia. Estoy solo, y me felicito de vivir en este país, el más a propósito para almas como la mía, soy tan dichoso, mi querido amigo, me sojuzga de tal modo la idea de reposar, que no me ocupo de mi arte. Ahora no sabría dibujar, ni siquiera hacer una línea con el lápiz; y, sin embargo, jamás he sido mejor pintor. Cuando el valle se vela en torno mío con un encaje de vapores; cuando el sol de mediodía centellea sobre la impenetrable sombra de mi bosque sin conseguir otra cosa que filtrar entre las hojas algunos rayos que penetran hasta el fondo del santuario, cuando recostado sobre la crecida hierba, cerca de la cascada, mi vista, más próxima a la tierra, descubre multitud de menudas y diversas plantas; cuando siento más cerca de mi corazón los rumores de vida de ese pequeño mundo que palpita en los tallos de las hojas, 
y veo las formas innumerables e infinitas de los gusanillos y de los insectos; cuando siento, en fin, la presencia del Todopoderoso, que nos ha creado a su imagen, y el soplo del amor sin límites que nos sostiene y nos mece en el seno de una eterna alegría; amigo mío, si los primeros fulgores del alba me acarician, y el cielo y el mundo que me rodean se reflejan en mi espíritu como la imagen de una mujer adorada, entonces suspiro y exclamo: "¡Si yo pudiera expresar todo lo que siento! ¡Si todo lo que dentro de mí se agita con tanto calor, con tanta exuberancia de vida, pudiera yo extenderlo sobre el papel, convirtiendo éste en espejo de mi alma, como mi alma es espejo de Dios!" Amigo... Pero me abismo y me anonada la sublimidad de tan magníficas imágenes (Goethe 1997: 27-28).

El sentir de Werther puede sonar trasnochado, obsoleto. Con todo, el pasaje es memorable porque el joven Werther ya no se ocupa de su arte, pero pinta con palabras lo que ve $\mathrm{y}$, hasta donde puede, lo que siente ${ }^{4}$. El abismo de lo sublime que lo atrapa es ya la nota romántica. Y, sin embargo, Goethe mismo no vivirá "en la angustia de manchar la gloria de su interior con la acción y la existencia”, como Hegel (2002: 384) caracterizará al "alma bella", pues Goethe es, entre otras cosas, la antítesis de tal romanticismo, formulado en el célebre pasaje de la Fenomenología del espíritu.

Werther podría ser, pues, un "alma bella”. Pero reparemos en la ficción de aquel sentir que se inmiscuye en la naturaleza que lo rodea y lo embarga. Siente la alegría de una primavera que refulge y a la que le dedica su máxima atención. Para hacer nítido el contraste entre esa forma de sentir y la

4 Vale la pena reparar en la figura literaria que Goethe emplea. Se trata de una carta de Werther en la que tiene lugar una curiosa ékphrasis: Werther describe con palabras las imágenes de la naturaleza, pero en su discurso las palabras para lo que ve y lo que siente son lo que hacen de él un mejor pintor. 
nuestra, traigamos a colación alguna experiencia contemporánea. Por ejemplo, es posible que quien se interne hoy en las selvas de Tambopata esté menos interesado en su alma, en la selva y "en la sublimidad de tan magníficas imágenes" que, simple y llanamente, en socializar lo que ve, también lo que come, si su aventura es sibarita. Bastaría que tenga a la mano un teléfono móvil y señal. A lo mejor, en algún punto, la selva engulle la señal. La selva no es, después de todo, la campiña primaveral de la localidad de Wahlheim en la novela de Goethe ${ }^{5}$, en la que hoy ciertamente habría conectividad. Pues sabemos, a fin de cuentas, que es cuestión de tiempo y técnica para que también allí, en la más profunda espesura de la selva, haya conectividad plena, por ejemplo con drones.

¿Qué nos dice el contraste entre esas dos formas de experiencia? Mientras que para Werther los "sucesos están para ser sentidos", para nosotros la experiencia se desliza en mostrar lo que se tiene frente a sí. La inofensiva publicación en imágenes de lo que los dispositivos técnicos están en condiciones de transmitir es el revés de actitudes precisas: las de indolencia e indiferencia con respecto a lo que se ve y escucha. Lo que tomamos por experiencia recoge lo ya sentido, a saber: lo ocurrido de alguna manera y registrado, en último término, en códigos numéricos para que pueda ser público. Ahora bien, a Perniola le interesa menos que la experiencia se haya convertido en espectáculo, cuanto lo que él llama el proceso de cosificación del sentir y que rastrea desde la modernidad.

5 El director de cine Werner Herzog explica sobre la selva: "And we, in comparison to the articulate vileness and baseness and obscenity of all this jungle, we in comparison to that enormous articulation, we only sound and look like badly pronounced and half-finished sentences out of a stupid suburban novel, a cheap novel". (Citado por la galería londinense de arte contemporáneo Pilar Corrias en la presentación de "TopoDendroPhilia": < http://www.pilarcorrias.com/exhibitions/topodendrophilia $>$ ). 
A primera vista, parece inconsecuente enlazar la cosificación del sentir con el transcurso de la modernidad, que hace de la subjetividad el eje de la experiencia, tanto en el empirismo como en el racionalismo. Pero a la luz de los análisis de Perniola se descubre que la subjetividad moderna es problemática, entre otras razones porque aspira a suspender las pasiones, que no puede entender sino como subjetivas. Del complejo espectro sobre las pasiones en la modernidad, Perniola no pone el énfasis en que sean las principales sospechosas de los males que aquejan a los hombres y a su vida en común, como sí lo hace el propio discurso de la modernidad. Discurso que ahora reconoceríamos como "ideológico", porque no advierte que la máxima ilustrada de servirse de la propia razón y librarse de los prejuicios viene también acompañada del oscuro gabinete en donde se ejecuta la vivisección, manipulación y cosificación de las pasiones. O, como lo entiende Foucault (2009: 215-225), esa misma máxima emplea un solo mecanismo, una misma mirada que vigila y homogeneiza para constituir y obtener un saber. La máxima exige un oxímoron, desde un punto de vista teórico, pues a la par que normaliza, individualiza. Pero desde el punto de vista del mecanismo que pone en práctica, el poder, es perfectamente comprensible que permita las desviaciones para castigarlas. La desconfianza en las pasiones, el desapego al que ella incita, la opacidad de la razón respecto de sus propios mecanismos sirven ciertamente a la configuración de un determinado modo de sentir moderno. Pero serán necesarios otros métodos para establecer cómo es el sentir actual. Perniola (2008: 13) lo llama impersonal y rastreará su formación con métodos arqueológicos y genealógicos.

Perniola observa que muchas posiciones filosóficas del siglo XX (el empiriocriticismo, el psicoanálisis, la filosofía de la mente, la hermenéutica, por ejemplo) se enfocan en el mismo problema: el hecho de que el sentir esté ya determinado. Difieren en sus razones para explicar tal situación. La de Pernio- 
la (2008: 31) es que el sentir se ha tornado impersonal porque se han socializado los sentidos. Ello significa principalmente dos cosas. Primero, que no puede pasarse por alto el papel de la estética, pues justamente ella despliega en sus prácticas y entramado conceptual el forjar un sentir común 6 , que, sin embargo, será imposible de realizar ${ }^{7}$. Las razones se harán patentes cuando consideremos sus dos variantes principales: la estética de la vida y la de la forma. Segundo, que dicho entramado va de la mano con el modo de realizar muchas de nuestras actividades cotidianas: mecanizadas en el universo de la burocracia, virtualizadas en el de las nuevas tecnologías. Ya en la lógica de la burocracia, Perniola afirma: "el sentir queda entre paréntesis, en suspenso, aplazado y destinado a otros lugares y contextos" (2008: 72); es decir, confinado en el régimen de lo estético. Pero una vez que el sentir queda establecido como lo opuesto al mundo mecanizado, también se abre la posibilidad de que la estética tome una preponderancia tal, que finalmente difumine y enrarezca el sentir.

Empecemos por considerar el segundo aspecto: suspender el sentir. La reconstrucción arqueológica del sentir debe exhibir la tajante separación entre el actuar y el sentir que la formación de la burocracia supuso. En efecto, en el mundo instrumentalizado, está, por un lado, la organización de las necesidades, por el otro, un modo de ser afectivo, emocional, contrapuesto al mundo instrumental burocrático. Esta misma oposición entre el sentir y el actuar mecanizado tiene

6 En lo que concierne a la estética del siglo XVIII, independientemente de la posición que tomen con respecto a un problema específico, es como si los autores valorasen una cosa ante todo: el gusto o capacidad que se pueda compartir con otros.

7 La variante histórico-filosófica de dicha imposibilidad la ofrece, como es sabido, Hegel en sus Lecciones sobre estética: un sentir común que en el arte clásico es consustancial con el éthos, es un modo superado por el espíritu. 
en las teorías relativas a las manifestaciones artísticas dos variantes: la estética de la vida y la estética de la forma (Perniola 2001, cap. I y II). Es importante advertir que ambas pueden reivindicar la existencia de un mundo interior, atribuible de suyo a personas sensibles y cultas. Pero se diferencian en que para la estética de la vida se alcanza un sentir compartido en la medida en que se pierde el sentir individual (pues su lógica es la de producir más y más experiencias vividas); mientras que en la estética de la forma se trata precisamente de renunciar al sentir individual para acogerse a la experiencia del objeto (Perniola 2008: 72-74).

Para dar cuenta, entonces, del sentir contemporáneo, Perniola ubica sus bases en una importante transformación de las acciones humanas, al menos desde el siglo XIX en adelante. Suspender el sentir viene a ser la máxima del mundo instrumentalizado. Pero, además, los modos en los que el sentir se opone a la lógica mecanizada e instrumental son consistentes con los desarrollos de la estética principalmente a partir del siglo XIX. Y lo que es también muy importante: una estética de la forma y de la vida no encajan ya en el universo romántico del "alma bella". Si el "alma bella" podía reclamar todavía una experiencia íntimamente personal, ni la estética de la vida ni la de la forma aspiran a lo personal. La primera, porque hace recaer el peso en el sentir común; la segunda, porque renuncia al sentir en aras del objeto. Es crucial para Perniola reconocerlas como maneras conducentes a un sentir impersonal, congruente con la disociación entre actuar y sentir, propia del mundo instrumentalizado.

Tratemos ahora el primero de los aspectos antes señalados: la forja de un sentir común. El análisis de la estética de la vida es particularmente importante a este respecto por la relación que se establece entre el sentir compartido y el individual. Una interioridad vivida en común, hacer colectivo el sentir, tiene como precio anular el sentir individual: 
A la estética de la vida la impulsa una pulsión de identificación inmediata, de participación, de reunión de almas: es un mundo de susurros y confidencias, de arrobamientos y afinidades, de influencias y de fusiones, de silencios elocuentes y de palabras cómplices, de recuerdos y añoranzas, de anhelos, de emociones, de afectos y de sensaciones que se sustentan recíprocamente y sintiendo el sentir. Lo que sorprende de este universo, representado y descrito por infinidad de escritores y novelistas de los siglos XIX y XX, hecho de momentos únicos, de frases memorables, de fabulaciones y de mitologías personales, de citas y de cartas, de conciertos y visitas a museos, de excursiones y paseos compartidos, de noches y días transcurridos con almas hermanadas, es que estuviese tan pagado de sí, que no tuviese otro fin que la experiencia de una interioridad vivida en común. Aunque es indudable que ha producido mucha literatura, y de gran calidad, no es menos cierto que su propósito principal ha sido el de ofrecer modelos de un sentir que se basta a sí mismo, que no sale del círculo vicioso de producir más experiencias vividas. Alguien acostumbrado al horizonte de lo ya sentido experimenta con todo ello cierta claustrofobia porque no puede situarse en el plano de lo concreto, así como cierta melancolía, por el enorme derroche que se le exige. Sin embargo, tal experiencia constituye una premisa esencial de lo ya sentido: en la estética de la vida, las facultades emocionales y afectivas aún no están socializadas, pero sí se hallan esencialmente colectivizadas. La estética de la vida funda una colectividad estética que se propone la tarea infinita de sentirlo todo (Perniola 2008: 75-76).

Reparemos en la forma como Perniola hace valer la tesis de que el sentir esté ya determinado. La arqueología del sentir debe hacer patentes las estratificaciones de lo ya sentido. El estrato más reciente es el de la socialización de los sentidos, pero es factible por dos procesos. En uno, las tendencias estéticas modernas, en especial aquellas que hacen de la experiencia vivida su razón de ser, se construyen junto con la 
disociación entre actuar y sentir, a la que nos constriñe el universo burocrático. En el otro, la socialización del sentir contemporáneo no es ya simplemente partícipe del mundo instrumentalizado; más bien, tal socialización se pliega a un nuevo fenómeno, para el cual Perniola acuña el neologismo de "mediacracia": con ella se refiere a "la idea de que la actividad eminentemente mediadora del pensar se ha trasladado al sentir" (2008: 32).

Es importante advertir que Perniola es absolutamente consecuente con su tesis inicial: la estética es la vía regia para comprender la condición contemporánea. La esfera del sentir, de la aísthesis, ha tomado tal preponderancia que usurpa las funciones del pensar. La actividad mediadora del pensar, en los términos estoicos: la recta razón y el convenienter vivere, queda anulada a favor de una experiencia especular, impersonal. Ahora bien, Perniola (2008: 16, 41) está lejos de creer que su tesis sea nihilista. Para explicar por qué, será necesario concentrarnos en el segundo de sus métodos: la genealogía del sentir.

\section{De antepasados: genealogía}

Se desea desarrollar ahora algunos de los principales conceptos empleados por Perniola para trazar una genealogía del sentir contemporáneo, impersonal. Los términos son antiguos: moneda, pneuma, aísthesis y ménos, pertinentes para rastrear orígenes e identificar ancestros.

\subsection{Moneda y pneuma}

Es importante tener presente el peso de las tesis de Perniola (2008: 129). El sentir impersonal, propio de nuestro tiempo, y el rasgo especular de lo ya sentido son inversa- 
mente proporcionales al esfuerzo, cuidado y atención para sentir de manera propia, que equivale a aprender a vivir. En el transcurso de la modernidad se habría ido mermando la capacidad emocional y afectiva, sea porque el sentir político toma a la vida como una carrera (siglo XVII), o porque el sentir económico la concibe como un cálculo ininterrumpido (siglo XVIII). Ambos anticipan que pueda integrarse, como ocurre en nuestros días, la dimensión afectiva con su factibilidad (2008: 123). Pero advirtamos que hacer realidad nuestros afectos ocurre bajo el modo del intercambio: la moneda corriente es la metáfora que se ajusta a la condición de la socialización de los sentidos e intercambio y circulación constantes de todo en todas partes (2008: 131).

Con aquella metáfora, Perniola busca hacer patente también cómo se estigmatiza y proscribe lo que elude la socialización y el intercambio, pero también cómo dicha elusión se configura en nichos perfectamente identificables (2008: 54). Por un lado, está la actividad ilimitada de atesoramiento de experiencias (como la que conocemos por obra de la buena y mala literatura, antes descrita). Por otro lado, está el despilfarro del consumo del arte y la literatura; despilfarro, porque son precisamente los diletantes, los personajes pródigos en transmitir sus experiencias en esos campos. Hacen gala de satisfacer una curiosidad en particular: sentir otra cosa. Queda pues un margen muy estrecho, un difícil punto de inflexión para sentir de manera propia.

La perspectiva que Perniola adopta para identificar cómo sentir de manera propia es la que le ofrecen los estoicos, nuestros ancestros. El sentir no tiene su origen en padecer el efecto de alguna acción que banalmente atribuimos a un "afuera". En la tradición de la filosofía están quienes, como los estoicos, sensualistas, atribuyen al sentir una cualidad activa. El sentir comporta una decisión, una práctica y un trabajo sobre uno mismo. La ascesis, en su sentido literal, 
significa justamente ejercicio. Señalemos que para esa misma tradición, entonces, el pensar no puede comprenderse como una operación u acto. El pensar es más bien receptivo, puesto que el sentir es selectivo: "Así como la dimensión afectiva es un acto intelectual, la dimensión intelectual es una recepción afectiva. Pensar es recibir lo que llega de fuera, acoger, aceptar lo que se nos presenta como extraño y enigmático" (2008: 130).

La dimensión afectiva es un acto, pues acarrea el ejercicio, y es intelectual, pues elige y discierne. El punto de inflexión para sentir de manera propia no es un padecer, sino un hacer: un "hacerse sentir" (2008: 129). La genealogía del sentir descubre su origen en lo activo y trastrueca los términos de la relación comúnmente admitida entre sentir y pensar. Para los estoicos, en efecto, el pensamiento es pneuma, soplo ígneo, imagen con la que se da a entender sobre todo "un fuego sembrador", "la fecundidad de un nacimiento instantáneo y centelleante" (2008: 132). Es importante detenerse en la imagen: el pensamiento puede trastocarse y asemejarse a todo; recibe lo que se le presenta, pues no tiene forma alguna; tampoco, entonces, la índole de lo material es meramente un contenido; por el contrario, el sentir es afecto, aísthesis en el pleno significado de sensibilidad, que como acto y ejercicio intelectual es un "hacerse sentir", en términos estoicos, un "obrar sobre uno mismo" (2008: 129).

\subsection{Aisthesis y ménos}

Puede que el camino seguido para explicar la genealogía del sentir y sus antepasados haya dejado muchos puntos oscuros. Oscuridad atribuible a la torpeza de intentar explicar con pocas ideas la cuidadosa reconstrucción de Perniola de la materia del sentir. Ahora bien, si ya la idea del pneuma contraviene a nuestro pensar corriente sobre qué es sentir, 
el asunto es más arduo aún cuando se trata de imaginarnos a nuestros ancestros. Perniola hace mención a los "antiguos maestros del sentir de Occidente" (2008: 134). Uno es el sabio estoico, que en la aísthesis permanece sereno. El otro es el poseído, cuya experiencia del ménos significa "ofrecerse con entusiasmo (...) [a] "fuerzas cuya dinámica resulta enigmática y contradictoria, o, en cualquier caso, extraña a la tranquila identidad del sujeto individual" (2008: 133). No necesitamos tratar de inmiscuirnos en el universo imaginativo y conceptual de los antiguos griegos. En cambio, sí interesa volver una vez más al método: la genealogía.

La genealogía de Nietzsche es impensable sin una "psicología". Claro que ella tiene poco que ver con nuestra actual disciplina, pues lo que estudia principalmente son los tipos de valoraciones. Prescindiendo de la tipología nietzscheana, lo que debe quedar claro con el recurso de la "psicología" es qué tipo de constitución anímica se condice con ciertos valores. O dicho de otra forma: qué configuración "psicológica" es necesaria para que se genere cierto valor. Si el peso recae meramente en la tipología, se pasa por alto una función principal exclusiva de la "psicología": ella no es otra cosa que lo que acontece en el orden de lo real, pero bajo el aspecto del símbolo o del valor. La "psicología" es un registro de lo simbólico, cuyo quiebre con relación a lo que acontece es de tal magnitud que recién entonces la cuestión del valor cobra algún sentido. Nietzsche empleó una expresión que entre tanto se ha vuelto insulsa: ¿cuál es el sentido de la vida? ${ }^{8}$ Nosotros quizá podamos comprender qué significa tal quiebre si afirmamos que puede afrontarse, como lo sugiere Perniola, de manera más o menos serena o poseída. Pongamos un ejemplo que esperamos sea claro: en el psicoanálisis de Freud prima la resignada certeza de que la instauración del orden de lo sim-

8 Sobre la expresión, véase Gerhardt, Volker. Friedrich Nietzsche. München: Beck, 1992, pp. 66 y ss. 
bólico es ineluctable; en el psicoanálisis de Lacan se trata de "desalojar una impostura": la de dedicarse a la "reeducación emocional del paciente". El lenguaje es, por consiguiente, también distinto: en Lacan cabe la diatriba como instrumento expresivo idóneo; en Freud, lisa y llanamente el análisis.

\section{3. "La enfermedad de las cadenas"}

Ha quedado pendiente una respuesta a la cuestión de por qué para Perniola, pese al descarnado y descorazonador diagnóstico que hace de nuestra situación contemporánea, no hay razones para ser nihilista. El nihilismo, de acuerdo con Nietzsche, concierne al problema del valor y se coloca en el registro de lo simbólico, esto es, de lo "psicológico". Si hemos comprendido bien las tesis de Perniola, hay maneras en las que el valor, atribuible solo en el orden de lo simbólico, se aloja activamente en la índole del sentir. Tal índole es, en la Stoa, atribuible a una cualidad material: la de la aísthesis. El sentir es una relación material, pero activa.

En principio, esa sola especificidad del sentir, su actividad, bastaría para entender por qué no cabe ser nihilista. En efecto, que al sentir actuemos, significa que podemos trabajar sobre nosotros mismos y que podríamos resistirnos al sentir impersonal. Pero las cosas no son tan fáciles. Reparemos en el rumbo que ha tomado para nosotros la aísthesis. Como disciplina filosófica y como ámbito autónomo de la experiencia es fruto de un momento histórico particular en la Europa del Siglo de las Luces. Baumgarten formula el nuevo

9 Lacan, Jacques. Escritos. México D.F.: Siglo XXI, 1971, p. 217. Se trata del capítulo titulado: "La dirección de la cura y los principios de su poder". 
significado que la palabra estética mentará en la modernidad (Bozal 2004, vol. 1: 19). Kant consigue zanjar el debate entre empiristas y racionalistas sobre la naturaleza de lo estético en dos pasos: haciendo explícito qué pretendemos con los juicios estéticos y estableciendo su legitimidad (y autonomía) con base en lo que ellos suponen o a lo que apelan: un "sentido común” estético, esto es, una misma capacidad humana para sentirse concernido universal y subjetivamente ${ }^{10}$. Entre tanto, se ha reconocido con Hegel el significado cultural (sc. "espiritual") del arte; se ha trazado un derrotero filosófico factible de ser interpretado como una "teoría especulativa del arte" (basado fundamentalmente en la manía o arrebato germánico por lo Ur-) (Schaeffer 2000); se ha planteado si lo que llamamos arte es una reconstrucción alentada por ciertas narrativas históricas (Danto 1999); se han rastreado los orígenes del arte contemporáneo en el moderno con base en la actitud ilustrada de la querella (Jiménez 2010); se ha reivindicado la modernidad en el arte como una manera de vivir impulsada por poetas (Hölderlin, Baudelaire, Rimbaud) (Midal 2007); se han estudiado algunas "escenas del régimen estético del arte", es decir, se ha ofrecido a la imaginación y al análisis casos de "esa fábrica sensible e inteligible de lo que llamamos "Arte"' (Rancière 2013); se ha mirado al arte bajo ángulos específicos y momentos determinados: la pintura de la posguerra europea como la del "tiempo del estupor" (Bozal 2004a); la vanguardia a finales de siglo como la del "retorno a lo real", es decir, exhibiendo una extraña temporalidad, paradójica: "cuando vuelve al pasado, la vanguardia también retorna del futuro, reubicado por el arte innovador en el presente" (Foster 2001: vii), etc. Menciono simplemente unos pocos casos de estudios concretos y dejo quizá lo

10 Cf. los parágrafos correspondientes a la "Analítica de los bello" en Kant, Emmanuel. Crítica de la facultad de juzgar. Traducción de Pablo Oyarzún. Caracas: Monte Ávila, 1992, pp. 121-155. 
principal en suspenso: cómo ciertas posiciones filosóficas en particular (hermenéutica, fenomenología, deconstrucción, teoría crítica y pragmatismo, principalmente) se ocupan de las manifestaciones artísticas.

El rumbo, pues, de la cuestión de la aísthesis en la modernidad indica que se ha enfatizado las capacidades del sujeto y se ha tratado a las manifestaciones artísticas como la esfera en la que dichas capacidades se prueban y encarnan ${ }^{11}$. Ahora bien, solo tangencialmente interesan a Perniola los asuntos tratados en tal ruta. Con relación a la aísthesis moderna es como si su posición - una defensa de la cualidad material del sentir, obrada a punta de su rasgo eminentemente activo y personal en lo que cabe para un neoestoicismo-, efectuase un giro para desasirse de posturas a combatir. Tal giro se condice con la advertencia de Nietzsche, de quien Perniola es, como hemos visto, un cuidadoso lector, de no sucumbir a la "enfermedad de las cadenas" (Nietzsche 1980, vol. 2: 702). Los errores "graves y sensatos" son la enfermedad que uno puede padecer o de la cual se es aún convaleciente. Librarse, curarse de ellos no es, sin embargo, suficiente. Arrogarse libertad de espíritu es lícito solo para quien "puede decir que vive por la alegría y no por ninguna otra meta" (Nietzsche 1980, vol. 2: 702) $)^{12}$.

11 Algunos ejemplos clásicos de ambos enfoques: Para Baumgarten, la aísthesis estaba íntimamente ligada a la antropología; Kant define a lo estético en términos de "cómo uno se siente afectado por una representación" (Kant, Crítica de la facultad de juzgar, \1, nota a pie); para Hegel "en las representaciones artísticas han depositado los pueblos su intuición suprema” (Hegel, Filosofía del Arte o Estética [1826]. Apuntes de F.C.H.V von Kehler. Traducción de D. Hernández Sánchez según la edición alemana de A. Gethmann-Siefert y B. Collenberg-Plotnikov. Edición bilingüe. Madrid: Abada, 2006, p. 51).

12 En la traducción de Humano, demasiado humano de Alfredo Brotons, hay una nota a pie que remite a una carta de Nietzsche a Adolf Baum- 
Dejemos de lado los problemas de la jovialidad nietzscheana y volvamos a Perniola. ¿De qué errores tendría uno que librarse, habida cuenta de la cuestión de la aísthesis desde la modernidad, para poder realmente atribuirse libertad de espíritu, autonomía?

Concluyamos respondiendo a aquella pregunta. Un primer grupo de errores concierne a problemas conceptuales que vale la pena considerar con cierto detalle. Hemos sostenido que en el neoestoicismo de Perniola el sentir es de índole material. Atarnos a la estéril contraposición entre físico y psíquico, entre cerebro y mente, entre tejido nervioso y sensación constituiría un error. No es cuestión de combatir la idea de que el sentir es privilegio de lo psíquico, de la mente o de la sensación. Tampoco es una simple inversión de las cualidades de una esfera en la otra. También Susanne K. Langer (1971: 21) intentó explicar "el proceso de sentimiento" por la vía

gartner el 23 (y no el 24 como se dice en la nota) de diciembre de 1878. Su esposa, Marie, había ayudado a Nietzsche a preparar el manuscrito para la imprenta de "El viajero y su sombra", que, por estas fechas, envía a su editor (cf. "Chronik zu Nietzsche's Leben". En Nietzsche, Sämtliche Werke, vol. 15, p. 94). El último aforismo se titula "Die goldene Loosung": "La liberación áurea". En la carta desea Nietzsche a Baumgartner "der englische Gruss: 'Friede auf Erden und den Menschen ein Wohlgefallen aneinander!"”. (Nietzsche, Friedrich. Sämtliche Briefe. Kritische Studienausgabe. Edición de G. Colli y M. Montinari. München/Berlin/ New York: Walter de Gruyter/dtv 1980, 8 vol., vol. 5, p. 374. La nota a la traducción cita mal a Nietzsche, pues él no envía un "saludo bíblico", sino un "saludo inglés". Con todo, la nota trae una observación interesante que citamos, sin conocer al autor, pues los editores españoles no lo indican: “"iPaz en la tierra y a los hombres complacencia unos para con otros!" Cita de Lucas, 2:14, en la traducción de Lutero, bastante diferente de la Vulgata: "Gloria Dios en las alturas y paz en la tierra a los hombres de buena voluntad'"' (Nietzsche, Friedrich. Humano, demasiado humano. Traducción de A. Brotons. Madrid: Akal, 1996, 2 vol., vol. 2, nota 201, p. 220). 
de tomar al sentimiento como parte de la acción vital y evitar que se le confine a "producto no material". Sin embargo, las diferencias entre Langer y Perniola son nítidas. No basta aclarar conceptualmente el símbolo como hace la tradición de la filosofía analítica a la que Langer pertenece. Es mucho más importante reconocer el peso que el pensamiento de la diferencia tiene en el sentir y la estética contemporáneos.

No es suficiente conceder, como hace Langer (1958: 9), que la tradición filosófica de la modernidad europea ha producido la literatura más esclarecedora sobre el mito, el ritual y el arte, para luego emplear la clave filosófica propia del siglo XX: el análisis lógico del concepto ${ }^{13}$. No cabe meramente la máxima de que "nunca deben despreciarse los antepasados venerables" (Langer 1958: 11). Desde la perspectiva de Perniola no podría hacerse un cabal análisis del símbolo sin explicar también por qué el sentir y el pensar estéticos contemporáneos se sostienen en una experiencia incompatible con aquella que está en la base de los grandes sistemas de tal tradición. Nuestro autor recurre a la obra de Freud para encontrar una explicación: "[En la obra de Freud] La psique se convierte en el modelo teórico de una lucha que excede largamente el propio modelo agonístico que se basa en el conflicto entre dos contendientes simétricos: no es posible,

13 En los trabajos de Langer, la cuestión del símbolo ocupa una posición central. Cf. también Langer, Susanne K. Feeling and Form. A Theory of Art developed from Philosophy in a New Key. New York: Scribner's Sons, 1953. En este libro dedica unas pocas páginas a Freud y a los "principios" desarrollados principalmente en La interpretación de los sueños (Darstellbarkeit, ambivalencia, condensación y sobredeterminación). Langer los presenta como modos de simbolización propios de la presentación y pensamientos no discursivos (cf. ibid., pp. 239-244). Esto es, los integra en un esquema que hace de ellos meramente modos expresivos de simbolización (cf. también: Susanne K. Langer. Los problemas del arte. Diez conferencias filosóficas. Buenos Aires: Infinito, 1966, pp. 125-139: "El símbolo artístico y el símbolo en el arte”). 
en este caso, establecer ninguna correspondencia entre el sistema inconsciente y el preconsciente, ya que el primero no aparece jamás en la escena de modo directo, ése es el lugar de la diferencia" (Perniola 2201: 197-198).

En la noción moderna de lo estético, aquella forjada en el Siglo de las Luces, el sentir se configura, en cambio, de forma diferente. Se sostiene en la posibilidad - o debemos decir en la confianza- del fin de una lucha, una paz por alcanzar, un estadio en el que los conflictos sean, al menos por un tiempo, paliados o atajados. Pero el sentir en el siglo veinte, anota Perniola, ha marchado por una dirección distinta, la de un conflicto aún mayor que el de oposición dialéctica, pues no se sostiene en una oposición de términos simétricamente polares. En la noción de diferencia, "entendida como noidentidad, como una desigualdad mucho más grande que el concepto lógico de diversidad y que ese otro, dialéctico de distinción", reconoce Perniola (2201: 194) el carácter específico del siglo veinte. Sería, pues, un craso error arrogarse libertad de espíritu y autonomía, sin haber resuelto y admitido la condición de la diferencia que nos es propia. Una condición tal que hace, por ejemplo, de la aspiración romántica al "alma bella" algo extraño y lejano .

Por último, un error inexcusable sería pensar de forma no histórica. En términos de Nietzsche: uno debe curarse de la enfermedad que consiste en tomar al hombre como algo atemporal, de cuyas manifestaciones da cuenta la historia en términos de un progreso. Pero ello nos conduce a otros problemas cuando, como hemos visto, el pensamiento de Perniola precisamente no está atado a la cadena del pensar ahistórico. Por el contrario, las raíces estoicas de su posición son esclarecidas vía la arqueología y genealogía del sentir moderno y contemporáneo.

Recibido: 09 de setiembre del 2015 Aprobado: 15 de diciembre del 2015 


\section{Bibliografía}

ARNIM, Hans Friedrich August von

1964 Stoicorum veterum fragmenta collegit Ioannes ab Arnim. Stuttgart: Teubner, 1964, 1 - 4.

BLÜHER, K. A.

1984 Historisches Wörterbuch der Philosophie. Darmstadt: Wissenschaftliche Buchgesellschaft. Tomo VI, 1984, pp. 777-779.

BÖHLING, F.

1998 Historisches Wörterbuch der Philosophie. Tomo X, 1998, pp. 176-186.

BOZAL, Valeriano

2004 "Orígenes de la estética moderna". En Historia de las ideas estéticas y de las teorías artísticas contemporáneas, 2 vol., Madrid: La Balsa de la Medusa.

2004a El tiempo del estupor. Madrid: Siruela.

DANTO, Arthur

1999 Después del fin del arte. El arte contemporáneo y el linde de la historia. Barcelona: Paidós.

ECKERMANN, Johann Peter

1946 Conversaciones con Goethe. Traducción de Jaime Bofill y Ferro. Barcelona: Joaquín Gil editores.

FOSTER, Hal

2001 El retorno de lo real. La vanguardia a finales del siglo. Madrid: Akal.

FOUCAULT, Michel

2009 Vigilar y castigar. México D.F.: Siglo XXI. 
GERHARDT, Volker

1992 Friedrich Nietzsche. München: Beck.

GOETHE, Johann Wolfgang

1997 Werther. Traducción de José Valor. Madrid: Edaf.

HEGEL, Georg Wilhelm Friedrich

2002 Fenomenología del espiritu. México D.F.: Fondo de Cultura Económica.

JIMÉNEZ, Marc

2010 La querella del arte contemporáneo. Buenos Aires: Amorrortu.

KANT, Emmanuel

1992 Crítica de la facultad de juzgar. Traducción de Pablo Oyarzún. Caracas: Monte Ávila.

LACAN, Jacques

1971 Escritos. México D.F.: Siglo XXI.

LANGER, Susanne K.

1971 Esquemas filosóficos. Buenos Aires: Nova.

1966 Los problemas del arte. Diez conferencias filosóficas. Buenos Aires: Infinito.

$1958 \quad$ Nueva clave de la filosofía. Un estudio acerca del simbolismo de la razón, del rito y del arte. Buenos Aires: Sur.

1953 Feeling and Form. A Theory of Art developed from Philosophy in a New Key. New York: Scribner's Sons.

MIDAL, Fabrice

2007 Petit traité de la modernité dans l'art. Paris: Pocket. 
NIETZSCHE, Friedrich

$1980 \quad$ Sämtliche Werke. Kritische Studienausgabe. Edición de G. Colli y M. Montinari. München/Berlin/ New York: Walter de Gruyter/dtv, 15 vol.

PERNIOLA, Mario

2014 Sobre el pensar barroco. Lima: Instituto Italiano de Cultura.

2008

Del sentir. Valencia: Pre-textos.

2007

"Cultural Turns in Aesthetics and Anti-Aesthetics". Filozofski vestnik. Volume 28, number 4.

2001 La estética del siglo XX. Madrid: La Balsa de la Medusa.

RANCIERE, Jacques

2013 Aisthesis. Scenes from the Aesthetic Regime of Art. New York: Verso.

SCHAEFFER, Jean-Marie

2000 Art of the Modern Age. Philosophy of Art from Kant to Heidegger. New Jersey: Princeton University Press.

WAHBEH, Farris

2006

"Review of Art and Its Shadow and the Sex Appeal of the Inorganic". The Journal of Aesthetics and Art Criticism. Volume 64, number 4. 